\title{
A Pilot Study of J95 in Secondary Care in Bosnia
}

Maj J P Owen

MB,ChB,MMedSc,MFOM,RAMC

\author{
Col AHM Macmillan \\ $\mathrm{MB}, \mathrm{ChB}, \mathrm{MPH}, \mathrm{MFPHM}$, late RAMC
}

\section{Med Branch, HQI (UK) Armd Div, BFPO 15}

SUMMARY: The Army's morbidity reporting system J95 was fashioned into a secondary care variant and a pilot study conducted in Multinational Division South West (MND SW) during Operation Resolute 2. Some codes were modified, in keeping with the concurrent primary care J95a amendment, which included separating 'Other Injury' event codes further into 'Sports Injuries' and 'Other Injuries'. The collection system encompassed both out-patient and in-patient data and appropriate disposal categories such as 'admit' and 'length of stay' were introduced. Participating units included the Hospital Squadron at Sipovo, the Hospital facility at Tomislavgrad and, via a liaison officer, UK admissions and referrals to the Force Hospital near Split. A four month period of compatible data was found. Over this period 1,410 personnel $(42.2 / 1,000 /$ month $)$ first attended out-patients with 337 requiring subsequent attendances $(10.1 / 1000 /$ month) and there were 425 admissions $(12.7 / 1,000 /$ month) from an average force level of 8,340 personnel. Nearly half the patients seen $(49 \%)$ had orthopaedic problems and this group provided over half of the admissions $(54 \%)$ and the bed occupancy $(53 \%)$. There was a sizeable out-patient work load for the physician (28\%). The pilot study showed that a $\mathbf{J 9 5}$ surveillance mechanism in secondary care was possible and informative. It gave indications of the impact of morbidity on the medical services and could help shape medical manning for future operations. It would be possible to adopt such a system in both the peacetime setting and in an international operational setting - in keeping with its primary care partner. It is recommended that $\mathrm{J95}$ secondary variant shoul $\$$ be continued on operations.

\section{Introduction}

British Forces (BRITFOR) deployed to Bosnia as part of the Implementation Force (IFOR) for a year from December 1995 to December 1996, with the majority of personnel serving within the MND SW. During that time a standardised morbidity reporting system, called J95 (1), was introduced for all the NATO forces in IFOR. J95 is designed to provide data on the number, type and outcome of attendances made by military personnel to their primary care medical centre or their unit medical officer.

Within MND SW the J95 system was developed further to provide additional useful information by reducing the broad scope of the categories 'Other Injuries' and 'Other Diseases' with the introduction of 'Sports Injuries', 'Training Injuries' and 'ENT Problems' classifications. The system was shown to work well in the primary care setting (2), demonstrating that almost half $(49 \%)$ of the working time lost within MND SW was due to orthopaedic problems and non-battle injuries.

The J95 system quantifies the impact of disease and injury on the effectiveness of the workforce in terms of working days lost. However this only reflects the working days lost for those patients seen, treated and then returned to work within the primary care setting. The patients that are admitted to hospital are not accounted for by this system, regardless of whether they are subsequently returned to work or evacuated to another secondary or tertiary care facility. There are hospital reporting systems in place that notify in-patient numbers and the length of stay, though it is not possible to relate this information to the data provided in the primary care setting. There are also a number of patients who are evacuated from theatre directly from the primary care setting. In order to complete the morbidity profile for personnel in Bosnic the J95a system was also modified for use in the aeromedical evacuation setting (3). This showed that over half $(54 \%)$ of the casualties evacuated from theatre had non-battle injuries, principally 'Other Injuries', 'Sports Injuries' and 'Internal Derangement of the Knee'.

In order to provide a comparable morbidity profile for both primary and secondary care, a modified version of the $\mathrm{J} 95$ system was piloted within the secondary care facilities in MND SW. The idea of a secondary care system had been mooted for use within the new Defence Secondary Care Agency but it needed a trial before its wider application could be assessed. Bosnia would be the ideal setting for such a pilot given a captive and known population at risk and a limited number of secondary care facilities. By keeping the ICD based event codes the same as those in concurrent use in the J95a primary care system, it was possible to provide information on aspects such as working days lost, which could be matched with the primary care data. By providing a J95 system for secondary care it was then possible to fill in the $\frac{D}{0}$ information gap between the data provided in the primary care setting and that provided at the airhead for those o being evacuated from theatre. The aim of this paper $N$ therefore is to report on a pilot study on a variant of J95 N for secondary care. 


\section{Methodology}

The data collection for secondary care was organised on similar lines to that used in primary care. Each military patient examined was recorded, the details varying slightly according to whether they were admitted or not. Non-BRITFOR personnel were not included in the data collection. For Outpatients the type of attendance (first or subsequent) and the principal diagnosis was noted along with the disposal. This could be 'Admit to the hospital', Return to unit (Fit, light duties or bed down/off all duty) or transfer, either in theatre or out of theatre (evacuate). For the Inpatients a similar set of data were recorded excluding the type of attendance and replacing the 'admit' data of the primary care model with the 'length of stay' (in days). The outcome on discharge remained the same as for Outpatients. In addition the gender of each patient was recorded.

An attempt was made to quantify the time spent travelling to receive secondary medical care. However this proved to be untenable for Inpatients, who were often unaware of the length of time in transit and was perceived by the hospital staff as an unnecessary extra piece of information to collect at a time when they were busy dealing with the patient's presenting medical complaint.

In order to ensure that the data were collected accurately and consistently, a designated reporting officer was identified at each of the hospital facilities. The hospital returns were collated at the end of each month and sent to HQ MND SW for analysis. Ar example of the hospital return record sheet is shown at Table 1. The definition of each event serial in ICD grouping was no different from that used in primary care (2). Local computer generated variations of the report were allowed to facilitate data collation and improve legibility of the returns.

Examination of the hospital admission and aeromedical evacuation data showed that nearly all BRITFOR personnel received their secondary care from three facilities; the Hospital Squadron with the Armoured Field Ambulance at Sipovo, the German/French Force Hospital at Trogir and the Hospital facility with the Parachute Field Ambulance at Tomislavgrad. It was not possible to identify different groups of personnel attending particular hospitals, therefore the data were grouped together to provide an overview from all the secondary care facilities. The number of personnel in-theatre was calculated from the daily personnel return (PERSREP) figures provided by the personnel staff department at HQ MND SW. The PERSREP for the mid-point of the reporting period was used as the denominator for calculation purposes.

A reporting officer was then identified and briefed at each location in order to ensure maximum participation from the units. At the Force Hospital in Trogir the Hospital Liaison Officer (Hosp LO) was the designated individual, being the only British officer in daily contact with the hospital staff and with routine access to the patients and their records.

\section{Results}

The planned period of data collection was for five months, though the first month's returns were only available from the two British facilities, due to complications in manning the Hosp LO appointment. Later there was a re-organisation of the medical facilities within MND SW, with a reduction in the number of hospital beds required. This resulted in the closure of the hospital facility at Tomislavgrad after only completing returns for the first two months. The continuity of the reporting was further affected by the rotation of the Armoured Field Ambulance at Sipovo after the first four months, with the loss of the last month's data for that facility. The result was that reliable data was only available from any individual facility for a four month period.

The PERSREP figure at the mid-point of the reporting period recorded 8,340 British personnel in theatre (Range over reporting period $=7,754-9,814$ ). Over the study period a total of 1,410 personnel were recorded as having first attended outpatients at the hospital facilities, this being a rate of 42.2 personnel per thousand per month $(42.2 / 1000 /$ month), with 337 requiring subsequent attendances (10.1/1000/per month). The in-patient data or revealed a total of 425 admissions $(12.7 / 1000 /$ month) of 으. which 111 required evacuation from theatro $(3.3 / 1000 /$ month). A summary of the data is shown if Table 2.

The profile of conditions requiring out-patient treatment is shown in Figure 1. Nearly half (49\%) of the patients were seen with orthopaedic problems ('Otho Injury', 'Other Musculoskeletal Problem', 'Sport Injurys 'Internal derangement of the Knee', 'Dorsopathies', 'RTA and 'Training Injuries'). Within the disease groups, the $\bar{\partial}$ majority are recorded as 'Other Diseases' accounting for $\stackrel{0}{0}$ nearly a fifth $(19 \%)$ of all attendances with a further $9 \%$ of cases being 'Dermatological problems'. The in-patient $\overline{0}$ profile is shown at Figure 2. The relative severity of the 3 orthopaedic problems encountered is reflected in the fact that they account for over half $(54 \%)$ of the admissions and $53 \%$ of the bed occupancy. 'Other Disease' accounts for $12.5 \%$ of the admissions with 'Dermatology problems' accounting for an additional $7.5 \%$ of the cases.

The profile for transfers out of theatre is shown at Figure 3. Orthopaedic problems constitute nearly three quarters $(72 \%)$ of the cases requiring transfer out of theatre. Within the group 'Other Injuries' forms the largest single event code $(21 \%)$ with 'Other Musculoskeletal' $(17 \%)$, 'Internal Derangement of the Knee and Joint' (12\%) and 'Sports Injuries' (10\%) making up most of the remainder. 'Other Disease' accounts for $10 \%$ of the cases and there was only a single patient with a dermatology problem requiring transfer out of theatre.

The number of events for the female component of the $N$ force were small and therefore, although, the mechanism $N$ was set up for gender comparisons, the pilot study did not reveal any useful data in this area. The validity of such comparisons in the future should be self evident but the 
Table 1

MND SW - J95a Secondary Care Reporting Form

This return is to reach Med Ops at HQ MND SW within 1 week of the end of each month.

Contact number: PTM 330 3580. Complete one sheet for male patients and one sheet for female patients. Only report those serials that have information to report (e.g. if 2 patients attend with intestinal disease and were given 6 days light duty between them, record as 1 CHARLIE 2 ECHO 6).

Secondary Care Unit:

Month: .96

THIS SHEET IS FOR MALE/FEMALE PATIENTS (Delete as appropriate).

\begin{tabular}{|c|c|c|c|c|c|c|c|c|c|c|c|c|}
\hline \multirow[t]{2}{*}{ Ser } & \multirow[t]{2}{*}{ Event } & \multirow[t]{2}{*}{$\begin{array}{l}\text { First } \\
\text { Attend }\end{array}$} & \multirow[t]{2}{*}{$\begin{array}{l}\text { Subseq } \\
\text { Attend }\end{array}$} & \multirow[t]{2}{*}{ Admit } & \multirow[t]{2}{*}{$\begin{array}{l}\text { Length } \\
\text { of stay } \\
\text { (days) }\end{array}$} & \multirow[t]{2}{*}{$\begin{array}{c}\text { Disp B } \\
\text { (days) } \\
\text { Light } \\
\text { Duties }\end{array}$} & \multirow[t]{2}{*}{$\begin{array}{c}\text { Disp C } \\
\text { (days) } \\
\text { Bedded } \\
\text { Down }\end{array}$} & \multirow[t]{2}{*}{$\begin{array}{c}\text { Transfer } \\
\text { to Hosp } \\
\text { (In } \\
\text { Theatre) }\end{array}$} & \multirow[t]{2}{*}{$\begin{array}{l}\text { Transfer } \\
\text { to Hosp } \\
\text { (Out of } \\
\text { Theatre) }\end{array}$} & \multicolumn{3}{|c|}{$\begin{array}{c}\text { Time Spent } \\
\text { Travelling } \\
\text { A=Less than } 1 \mathrm{hr} \\
\mathbf{B = 1 - 5} \text { hours } \\
\text { C=Exceeds } 5 \text { hours } \\
\text { Total no. of } \\
\text { personnel }\end{array}$} \\
\hline & & & & & & & & & & $\mathrm{A}$ & $\mathrm{B}$ & $\mathrm{C}$ \\
\hline 1. & $\begin{array}{l}\text { Intestinal infectious } \\
\text { disease }\end{array}$ & & & & & & & & & & & \\
\hline 2. & $\begin{array}{l}\text { Syphilis and other } \\
\text { STDs }\end{array}$ & & & & & & & & & & & \\
\hline 3. & $\begin{array}{l}\text { Other infectious } \\
\text { disease }\end{array}$ & & & & & & & & & & & \\
\hline 4. & $\begin{array}{l}\text { Alcohol and drug } \\
\text { abuse }\end{array}$ & & & & & & & & & & & \\
\hline 5. & Mental disorders & & & & & & & & & & & \\
\hline 51. & Stress reaction & & & & & & & & & & & \\
\hline 6. & Eye disorders & & & & & & & & & & & \\
\hline 7. & Asthma & & & & & & & & & & & \\
\hline 8. & $\begin{array}{l}\text { Resp disease other } \\
\text { than asthma }\end{array}$ & & & & & & & & & & & \\
\hline 9. & $\begin{array}{l}\text { Disease of the oral } \\
\text { cavity }\end{array}$ & & & & & & & & & & & \\
\hline 11. & $\begin{array}{l}\text { Other digestive } \\
\text { system disease }\end{array}$ & & & & & & & & & & & \\
\hline 12. & $\begin{array}{l}\text { Contraception } \\
\text { gynae and preg }\end{array}$ & & & & & & & & & & & \\
\hline 13. & $\begin{array}{l}\text { Dermatological } \\
\text { problems }\end{array}$ & & & & & & & & & & & \\
\hline 14. & $\begin{array}{l}\text { Internal der of knee } \\
\text { and joint }\end{array}$ & & & & & & & & & & & \\
\hline 15. & Dorsopathies & & & & & & & & & & & \\
\hline 16. & $\begin{array}{l}\text { Other } \\
\text { musculosketal }\end{array}$ & & & & & & & & & & & \\
\hline 17. & Injuries from RTAs & & & & & & & & & & & \\
\hline 18. & $\begin{array}{l}\text { Other non-battle } \\
\text { injuries }\end{array}$ & & & & & & & & & & & \\
\hline 19. & War injuries & & & & & & & & & & & \\
\hline 20. & $\begin{array}{l}\text { Heat/cold cas (temp } \\
\text { and light) }\end{array}$ & & & & & & & & & & & \\
\hline 21. & $\begin{array}{l}\text { Complications of } \\
\text { medical care }\end{array}$ & & & & & & & & & & & \\
\hline 22. & Other disease & & & & & & & & & & & \\
\hline 24. & $\begin{array}{l}\text { Disorders of Ear, } \\
\text { Nose and Throat }\end{array}$ & & & & & & & & & & & \\
\hline 25 . & $\begin{array}{l}\text { Injuries due to } \\
\text { training }\end{array}$ & & & & & & & & & & & \\
\hline 26. & Injuries due to sport & & & & & & & & & & & \\
\hline
\end{tabular}


Table 2

Summary of J95a Secondary Care Data; Jul - Nov 96.

\begin{tabular}{|l|r|c|}
\hline Parameter Recorded & Totals & Rate/1000/Month \\
\hline First Attendance & 1410 & 42.2 \\
Subsequent Attendance & 337 & 10.1 \\
Admission & 425 & 12.7 \\
Length of Stay (Days) & 1545 & 46.3 \\
Disposal B-Light Duties (Days) & 1165 & 34.9 \\
Disposal C-Bed Down in Unit (Days) & 44 & 1.3 \\
Hospital transfer (Within theatre) & 6 & 0.2 \\
Hospital transfer (Out of theatre) & 111 & 3.3 \\
\hline
\end{tabular}

small numbers here meant that female figures were put together with the male ones into a combined Table 1 and Figures 1-3 and small number comparisons were not attempted in this case.

\section{Discussion}

The use of the J95a morbidity reporting system within the secondary care environment was developed in order to fill an information gap for those patients who were not treated solely within the primary care setting.

There were some problems in putting the system in place, as a few of the hospital clinicians initially did not see the benefits of completing a further set of returns which would not immediately benefit, in their eyes, the individual patients. There was also insufficient time and resources to involve the clinical staff at the Force Hospital in Trogir in the reporting process.

This resulted in the burden of the data collection and extraction falling on the designated reporting officer in each location. This in turn resulted in much of the information being taken retrospectively from the patients' case notes and discharge summary sheets. As elements of the data required, such as the length of stay and disposal/transfer, could only be provided at the time of discharge, this did, in effect, prove to be the most suitable time for information collection.

It is accepted that the data collection was not complete over the planned five month duration. However there was a core period of four months when the hospital sites were submitting their reports. This was therefore the period used in calculating the attendance and admission rates. As the hospitals admitted BRITFOR patients from all locations and did not have specific geographical areas of responsibility, it was not possible to calculate rates for individual hospitals. Therefore all the facilities were grouped together and the PERSREP figure used as the denominator in calculations. As a result of using the divisional figures, there was no effect on the data from closing the secondary care facility at Tomislavgrad as the patients were admitted elsewhere. There were other nonBritish hospital facilities within IFOR and therefore BRITFOR personnel could be admitted elsewhere. However a review of the admission and discharge reports held at HQ MND SW showed that this occurred in only 13 cases, two of whom were subsequently transferred to hospitals included in the data collection.

The data that was collected shows that the predominant patient load on the secondary care facilities results from 3 orthopaedic problems. The proportion of the overall cases $\stackrel{\Phi}{\Omega}$ made up by this group increases from Outpatients (49\%), $\bigcirc$ to Inpatients $(54 \%)$ and then again amongst those requiring transfer out of theatre $(72 \%)$. The opposite can $\%$. be seen with the disease profile, where 'Other Disease' and $\Rightarrow$ 'Dermatology problems' make up over a quarter $(28 \%)$ of all patients seen in Outpatients, though they only account for $10 \%$ of those needing transfer out of theatre.

Closer examination of the 'Dermatology' group and $\frac{\mathscr{D}}{\bar{\phi}}$ discussion with the clinicians in Sipovo elucidated the fact that the vast majority of these cases were surgical in w nature - benign skin lesions for excision. The lesions are $\overrightarrow{0}$ ICD dermatology coded hence the J95 profile which was not, therefore, an indicator of physician workload.

Indeed the data clearly indicate the level of specialist activity and bed occupancy related to disease groups sufficiently to inform or confirm staffing levels, structural issues such as size of an out-patient department and bed $\overrightarrow{\vec{A}}$ numbers, and indicate equipment requirements. The case for the orthopaedic surgeon in-theatre is self evident from N the data as is the need for a physician in a force of this ${ }_{\mathcal{C}}$ size. Longer term collection of J95 secondary care data을 could thus help inform planning for future deployments -

Whilst although this pilot study was undertaken in $\overrightarrow{\mathrm{p}} \mathrm{c}$ operational setting it would appear to have shown relevance to peacetime practice and could inform boif purchaser, i.e. Land Command, and provider, i.e. Defente Secondary Care Agency, alike by linking morbidity $\Phi^{\circ}$ clinical activity to structures. The impact of morbidity medical resources would sit comfortably in parallel wi the impact of morbidity on the military workforce atso shown in the J95 primary care data set. Just as J95\% primary care has beget EpiNato (4), the multi-national@ version, the ICD based nature of $\mathbf{J} 95$ secondary care has $\overrightarrow{0}$ international possibilities and should be adopted by 3 NATO in Bosnia.

\section{Conclusion}

This trial has shown that it is possible to collect J95 morbidity data within the secondary care setting However the data should be confined to those facts that $\frac{\bar{\sigma}}{\mathrm{\sigma}}$ can be extracted from the Outpatient notes and Inpatient discharge summaries. The data collection should be undertaken by a designated reporting officer, though not 3 necessarily one of the hospital clinical staff. Individualsecondary care facilities can not be studied separately을 when collecting morbidity data as it is not feasible to define an exclusive military population for each hospital.

The morbidity profile seen shows the preponderance of $\frac{D}{O}$ cases classified as 'Other Injury' or 'Other Disease', despite modifying the event codes classifications and $\mathcal{O}$ introducing the 'Sports injuries', 'Training injuries' and 'ENT problems' in order to reduce the scope of the 'Other' categories. In view of the high proportion of orthopaedic problems encountered it would be worthwhile to examine 


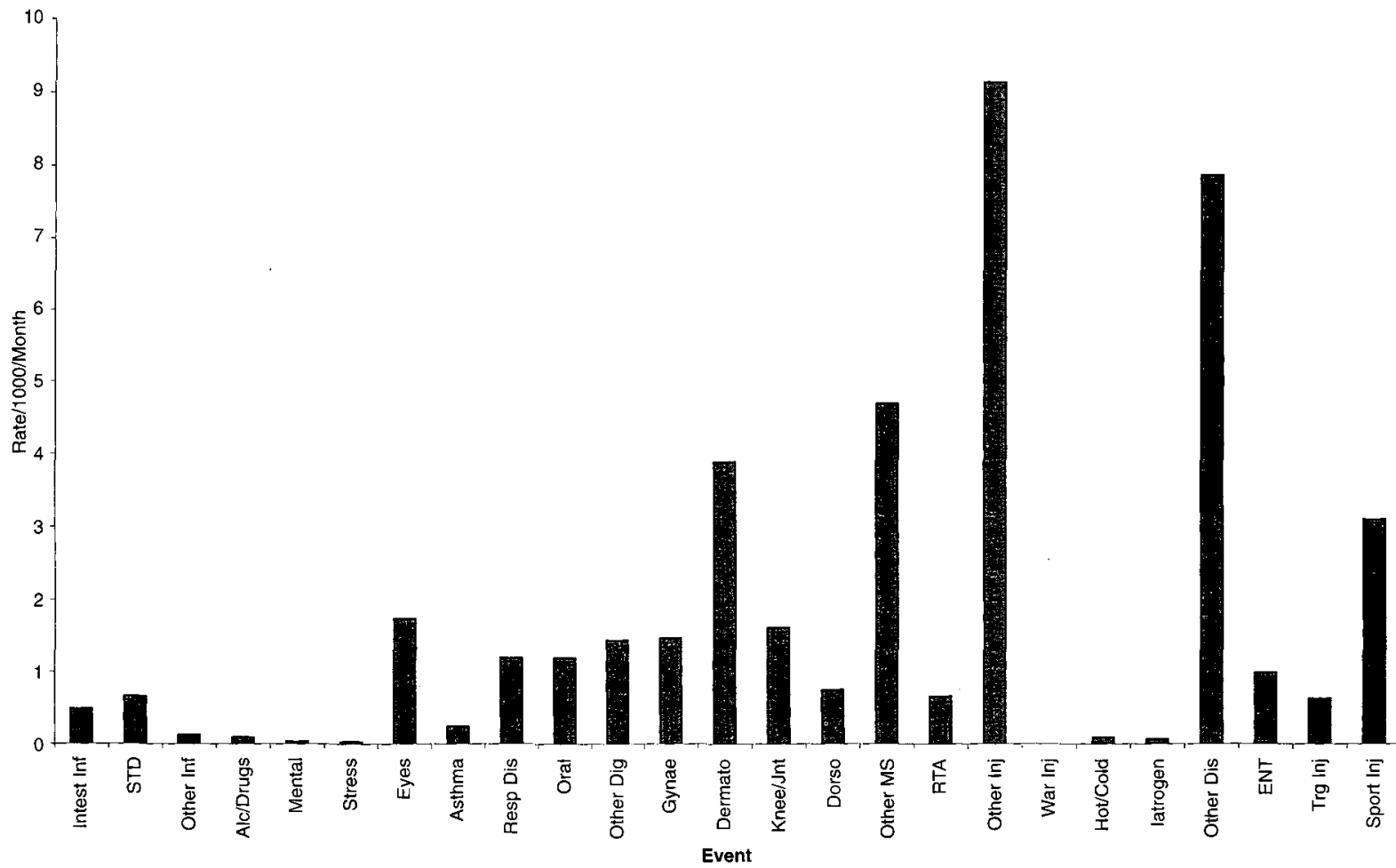

Fig 1. Rate of First Attendances For Outbatients in MND SW (.Jul-Nov): SIPOVO. TSG. TROGIR

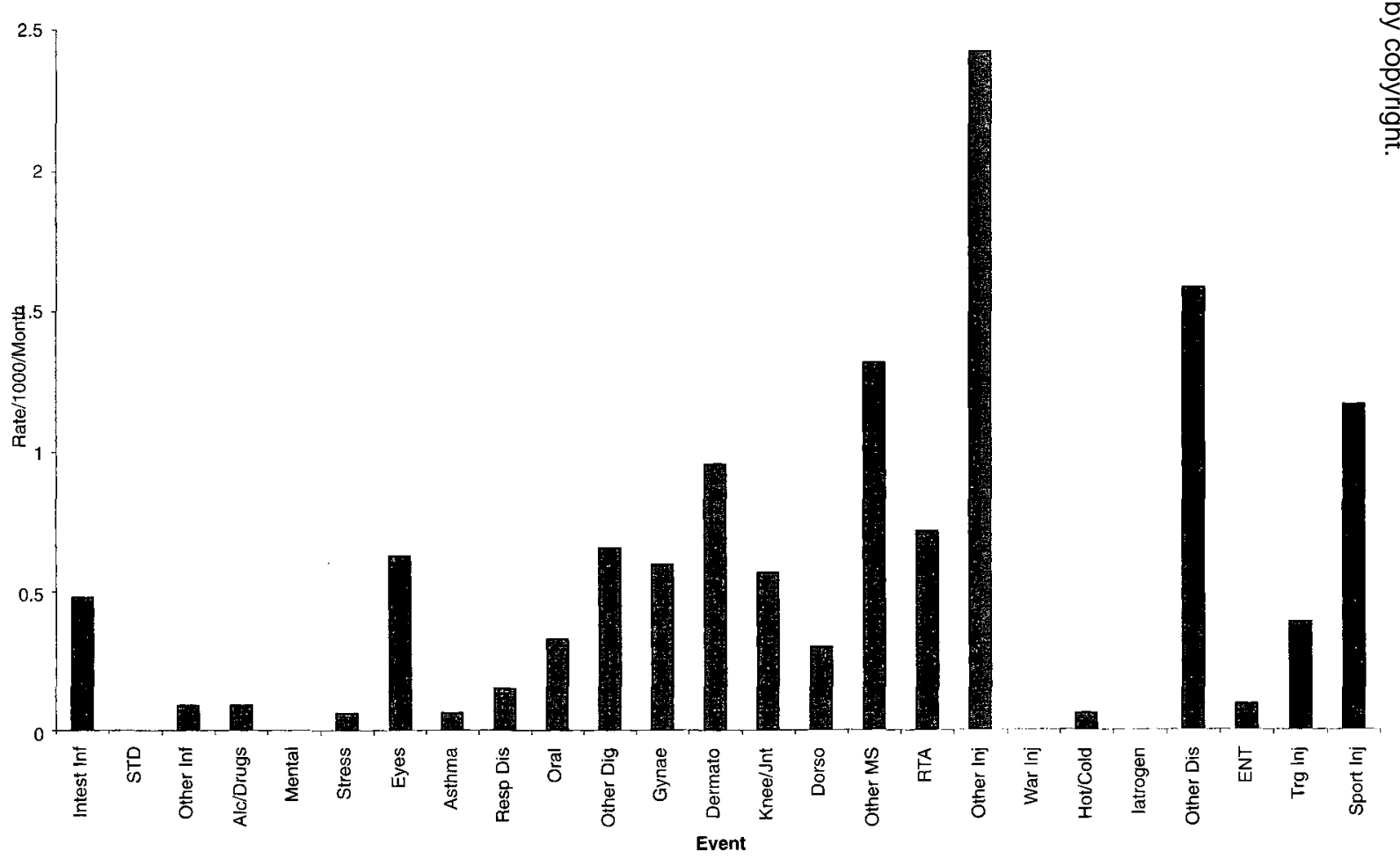

Fig 2. Rate of Inpatient Admissions in MND SW (Jul-Nov): SIPOVO, TSG, TROGIR 


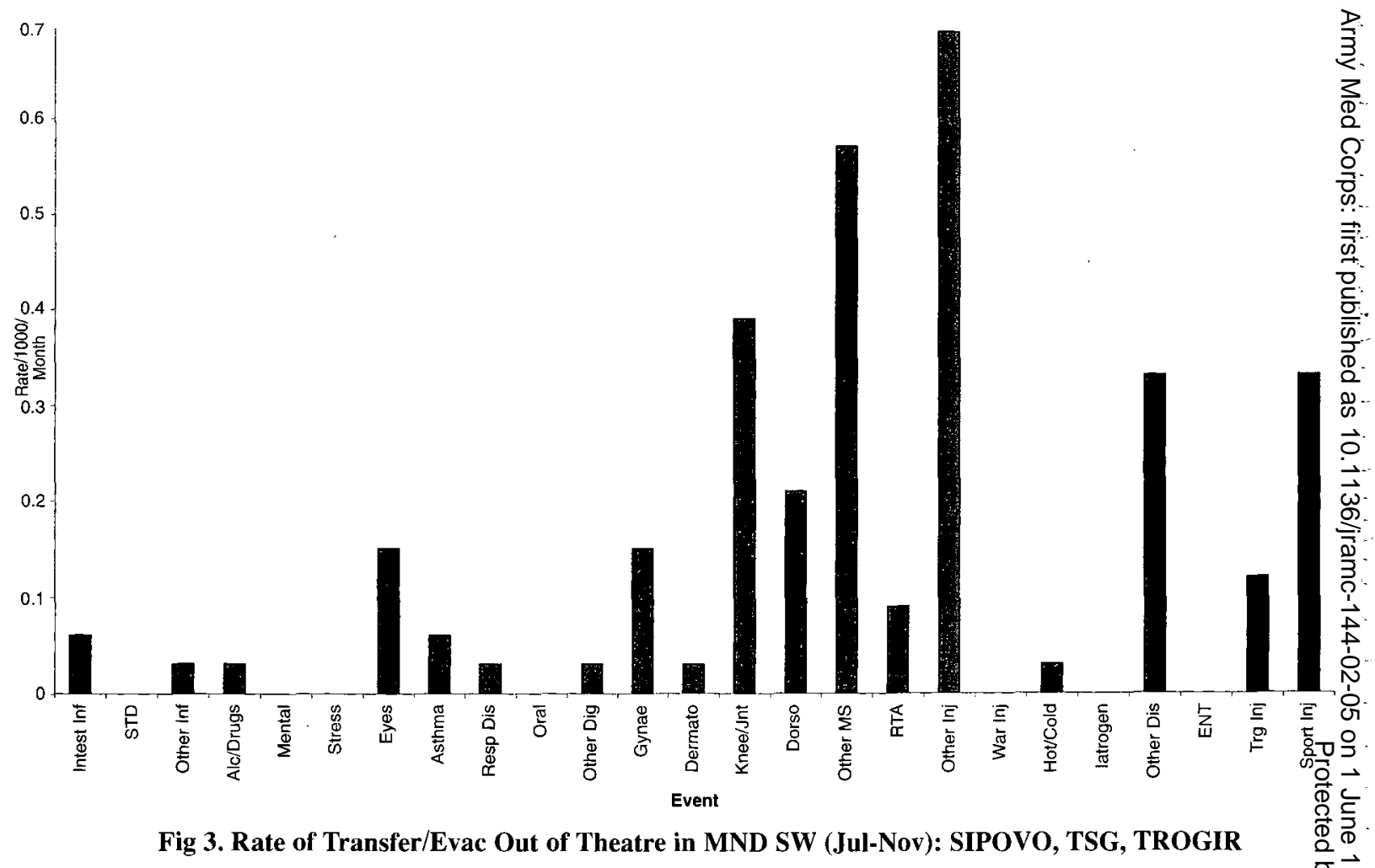

the aetiology of the injuries further in order to identify any activities that could be modified in order to reduce the injury burden.

The pilot study has indicated that the system has a utility in informing and monitoring medical resource requirements and thus could be an aid to future resource planning. It has also filled in the holes of the working days lost profile of the deployed force. It should be adopted as a routine surveillance system over secondary care facilities on operations. It could equally be used in a peacetime setting and an international operational setting.

\section{Acknowledgments}

The authors would wish to pay tribute to the Hosp LO at the Force Hospital, Maj P Whittlesey QARANC(V), for her sterling work in transcribing the German hospital dagaco into J95 and ICD format.

\section{REFERENCES}

1. JefFERSON TO, Demicheli V, Macmillan AHM. Pilot Study for the Introduction of the J95 Health Data市 Collection. J R Army Med Corps 1996; 142: 25-29.

2. OWEN JP, MACMILlaN AHM. J95 Health Surveillance $\frac{0}{3}$ in Multinational Division Southwest (Bosnia): July November 1996. J R Army Med Corps 1998; 148: 18 23.

3. OWEN JP. Aeromedical Evacuation of BRITFOR Personnel from Bosnia. HQ 1 (UK) Armd Div 1110 Med dated 7 Feb 97.

4. JEFFERSON TO. J95, The Morbidity Surveillance System. J R Army Med Corps 1997; 143: 71-72. 